\title{
An Assessment of Psychopathology in Drug Addicted Victims: A Clinical Psychologist Perspective
}

\author{
Kasomo Daniel \\ Department of Religion, Theology and Philosophy, Maseno University, Kenya Faculty of Psychology St. James the Elder Theological \\ Seminary, Jacksonville, Florida, USA
}

\begin{abstract}
There has long been an effort to develop a single unifying theory to explain the phenomenon of drug dependence. Some of these efforts have focused on psychoanalytic theory, various aspects of ego functioning, socio-economic factors, and physiological effects of drugs. Most investigators, however, have focused on character pathology in addicts and have considered addiction as representing one form of character disorder. There has been a lack of emphasis on various psychiatric conditions which could predispose and accompany drug dependence. This paper considers drug dependence as a multi-etiological phenomenon. This paper explores various psychiatric problems identified in drug dependent individuals and how they interact with the drug dependence. The use of psychotropic agents in the treatment of drug dependent persons is also explored.
\end{abstract}

Keywords Abuse, Addiction, Drug, Pathology

\section{Introduction}

Drug use and drug dependence is a multi-etiological phenomenon which includes social, economic, psychological, and physiological factors. Included in this opinion is the belief that there is a high incidence of psychiatric problems in drug dependent individuals and that specific psychiatric syndromes may lead an individual to become drug dependent. Historically, most of the medical profession has viewed addiction in terms of character pathology, with only little attention paid to other contributing factors. The aim of this paper is to expand on the multi-etiological theory of drug dependence, viewing addiction (especially narcotics addiction) as it relates to various psychotic states, depression, borderline personality, character pathology, and situational stress with time-limited addiction. I will also briefly examine the use of various psychotropic agents in the treatment of certain drug dependent individuals. A key point is that careful individual evaluation must be made of each drug dependent person in order to develop an adequate treatment plan.

\section{Historical Perspective}

In the past fifty years there has been a steady progression and shift in our understanding of the nature of addiction and

* Corresponding author:

dkasomocounselling@yahoo.com (Kasomo Daniel)

Published online at http://journal.sapub.org/ijap

Copyright (C) 2012 Scientific \& Academic Publishing. All Rights Reserved its contributing factors. Until recently, much of the work in this area was generated by a few individuals whose primary interest was formulating a single theoretical network for understanding addiction. Investigators focused on one or more of the theoretical areas in which addiction was viewed, including the intrapsychic (psychoanalytic and other psychological factors), the social (including socio-economic factors), and the physiological (effects of drugs on the biological organism). A brief review of some of the major literature in this area will help familiarize the reader with the theoretical trends in the addictions and will also serve to highlight some of the major public and scientific controversies regarding the etiology of addiction and methods for treatment of the drug dependent individual.

Early psychoanalytic work is scanty and focuses mainly on the libidinal aspects of drug use relating to instinctual drives and object relations. Kolb (1927) suggested that personality characteristics of the user determined both the pattern of drug use and the subjective effects of the drug. Though his terminology is moralistic and was undoubtedly influenced by the prevailing notion that use was ipso facto evidence of deviance, Kolb was careful in his sampling and thorough in reporting on a variety of influencing factors in his subjects. In 1933, Rado identified the presence of depression in many of the addicts he studied, yet he tended to emphasize the regressive function which drugs had for the user. In the early 1950's, Glover emphasized the ego defensive role of drugs in protecting against paranoid thinking and overt psychosis. After the establishment of the Federal prison for narcotic addicts at Lexington, Kentucky, a new and intensive effort was undertaken to understand narcotic addiction. While initial efforts focused on the physiological 
aspects, later efforts were directed toward the psychological characteristics of the narcotic addict. Wikler $(1952,1953)$ focused on addicts' anxieties related to aggression and sexuality and the manner in which drugs were used to relieve these anxieties. In subsequent decades, Vaillant (1966) and Wishnie (1974) pointed out that depression was often an underlying syndrome in the addict and that the narcotic served to defend against and mask depression.In a review by Treece (1977) various psychological profiles of drug dependent individuals as measured on the MMPI show no consistency and suggest that the profiles are strongly influenced by the setting in which the test is given, the sampling technique, and the treatment status of the individual. Gerard and Kornetsky (1954) and Chein, Gerard, Lee, and Rosenfeld (1964) were the first to look at the phenomenon of adolescent addiction in a ghetto setting and the first to attempt to synthesize the theoretical formulations up to that point. They understood both the specific effects of the drugs and their role in the psychological economy of the individual. Subsequent works by Krystal and Raskin (1970), Wurmser (1974), and Khantzian (1974) have focused on the adaptive use of drugs in maintaining ego stability, managing painful and sometimes overwhelming affects, tolerating narcissistic injury, and defending against certain affects, particularly rage and aggression. A number of recent studies illustrate the presence and variety of psychopathology in drug dependent individuals presenting for treatment. Reports by Benvenuto and Bourne (1975), Wesson, Smith, and Lerner (1975), McKenna (1978), and Stauss, Ousley, and Carlin (1977) stress the high degree of psychopathology among polydrug users. A report by McKenna and Khantzian (1979) compares a group of polydrug and narcotics users according to ego functions and psychopathology.The data in that report compares scores on the Psychiatric Status Schedule of Spitzer and Endicott among narcotics users, polydrug users, and combination narcotics and polydrug users. The results indicated a degree of psychopathology in all these groups to be similar to or greater than that for a group of psychiatric inpatients. Furthermore, there were no significant differences among the various drug dependent groups. Since all the patients in the drug dependent sample were entering a drug detoxification unit, they could be expected to be experiencing more symptomatic distress, thus somewhat skewing the results. Even taking this into account, we feel the results point to significant disturbance in drug dependent individuals entering drug treatment. Khantzian (1978) develops the theory that addicts have deficiencies in those component ego functions related to "self care and selfregulation," hypothesizing that these deficiencies or defects in self care occur as a ". Result of failures to adopt and internalize these functions from the caring parents in early and subsequent phases of development." Thus we can see that during the last 50 years there has been a continual expansion of efforts to understand the psychological factors underlying drug dependence. Much of the current work is aimed at further examining the various aspects of psychopathology seen in drug dependent individuals.

\section{Clinical Perspective}

Psychosis in Drug Dependent Individuals. Psychic distress often precedes and usually accompanies drug dependence. Nowhere is this more evident than in those individuals with incipient or already present psychotic states who seek relief from their symptoms by attempting self-treatment with narcotics. In at least two separate methadone maintenance programs we have found a history of psychosis predating addiction to narcotics in approximately $10 \%$ of the patients in treatment. (Since there are fewer narcotic dependent persons in treatment than in the general population, this figure may indicate that those with a history of psychosis are overrepresented in methadone maintenance programs.) These individuals are generally unfamiliar with mental health resources, are not particularly psychologically-minded, yet are aware that something is seriously wrong. They frequently give a history of searching for a substance to relieve their symptoms, typically stopping their search when they begin using opiates, particularly heroin. This is not surprising since heroin is an extremely potent psychotropic agent and, as seen in the histories of some of our patients, has an effective antipsychotic action. They have discovered a psychotropic drug that is effective in alleviating the thought and affective disturbances commonly found in psychotic states such as schizophrenia or bipolar affective illness. (This use of narcotics by psychotic persons is pharmacologically reasonable, since narcotics, particularly morphine, were used as a common treatment to control acute psychotic symptoms prior to the discovery of phenothiazines.) In 1973 McKenna, Fisch, Levine et al. reported on three individuals on methadone maintenance who had histories of psychosis (diagnosed as paranoid schizophrenic, manic depressive illness, and psychotic depression). In each case the psychotic symptoms were controlled with methadone (at doses ranging from 60 to $150 \mathrm{mg}$ ). The three patients had repeatedly attempted detoxification and experienced a return of their symptoms when their dose of methadone was decreased below $20 \mathrm{mg}$. Each attempted to remain drug free and invariably returned to drug use; eventually, each returned to the methadone maintenance program. When it became apparent that the methadone was acting as an antipsychotic agent, we attempted to alter their treatment regimen. The first patient, who had symptoms of bipolar affective illness, was successfully switched to a regimen of lithium carbonate plus continued individual and group therapy. He remained symptom free and off narcotics for one year, was stabilized on lithium, and subsequently left the region and was lost to follow-up. The second patient, who developed a psychotic depression when drug free, eventually stabilized on a daily regimen of methadone $(56 \mathrm{mg})$, amitryptyline $(150 \mathrm{mg})$, and diazepam $(40 \mathrm{mg})$. Though he tried to remain narcotics free following detoxification, he returned to narcotic use and ultimately chose to remain on methadone. The third patient detoxified for the second time in June, 1972. Nearing completion of detoxification, he began experiencing auditory hallucinations, left the program, 
and continued to experience symptoms of a paranoid schizophrenic reaction which continued until December, 1972, when he reapplied for methadone maintenance. He refused treatment with phenothiazines and was induced onto $60 \mathrm{mg}$ per day methadone maintenance on the general psychiatry unit. Following stabilization on methadone and the diminution of his psychotic symptoms, he was transferred to the methadone maintenance clinic where he preferred to be treated. Berken, Stone, and Stone (1978) have reported a case in which methadone was used to control schizophrenic rage in a nineteen-year-old woman. They noted a history of heavy street drug use, including heroin, typical schizophrenic symptoms, lack of response during 13 hospitalizations to usual psychotropic drugs (including lithium carbonate, tricyclic antidepressants, major and minor tranquilizers). Methadone, as well as other narcotics which the woman used on the street, calmed her periods of rage and significantly improved her self image so that she was able to work successfully in psychotherapy while remaining on methadone maintenance. For these people who attempt to self-medicate psychotic symptoms, problems occur because 1) narcotics are illegal; 2) these individuals are thus forced into a lifestyle and subculture not necessarily of their own choosing; 3) they are viewed by the public and institutions in our society as deviant and criminal rather than as individuals in need of mental health services; 4) they usually suffer from problems with self esteem associated with addiction. Normally, we would expect such a population to be treated in the traditional mental health system. Instead, they end up in drug treatment programs, are often on methadone maintenance, and they experience the attendant stigma associated with these programs. This situation presents a dilemma for patients, drug treatment program staff, and psychiatric program staff. Psychiatric outpatient (and inpatient) programs are reluctant to treat drug dependent individuals; staff frequently feel they lack the pharmacology background necessary to detoxify drug dependent persons and also the skills needed for follow-up treatment of persons they consider to have character disorders. On the other hand, drug dependent individuals with histories of psychiatric disorders frequently prefer the identity of "drug addict" to that of "psychiatric patient." We have not found a solution to this problem and currently have certain patients on combinations of methadone and antipsychotic drugs (phenothiazines, butyrophenones) and use our inpatient psychiatric service if hospitalization is required.

\section{Depression}

Another major psychiatric syndrome that we see repeatedly in patients on methadone maintenance is depression. This finding has been noted as well in other drug treatment programs. Weissman, Slobetz, Prusoff, et al. (1976) and Senay (1977) report at least moderate depression in approximately one-third of two separate groups of patients on methadone maintenance. In a study we are currently con- ducting, 2 we have found a $51 \%$ rate of moderate depression in 35 patients tested to date. This rate has held constant for patients entering the program (tested 3 weeks after beginning methadone) and those in the program for variable lengths of time. (This percentage may decrease as our sample size increases.) These findings raise a number of interesting and important questions. Why is there such a high incidence of depression in patients on methadone maintenance? Does the depression precede or do symptoms follow addiction to heroin or other opiates? It is difficult to answer either of these with much certainty. Some individuals report depressive symptoms (though they rarely use the term depression) prior to using narcotics. For these people, the narcotic use may be an attempt at self-treatment, a use similar to that by the previously described individuals with psychotic symptoms. More often, though, patients describe the onset of depressive symptoms after they have become addicted. They relate the symptoms to their feelings about themselves as "addicts" and the ostracization they feel from the rest of society. The consequent lowering of self esteem is, of course, a central feature of depression. Whether the symptoms precede or follow addiction, they play an important role in the life of the patient and need attending to in a drug treatment program as they would in any psychiatric setting.

\section{Character Pathology}

The question of character pathology invariably arises in any discussion of addiction. In the older terminology, addiction of any sort was considered a specific character and behavior disorder. It was categorized along with antisocial personality, passive aggressive personality, and so on. In the newer proposed classification (DSM III), various addictions are separated and classified under Organic Mental Disorders and Substance Use Disorders. There is an association made, however, between Substance Use Disorders and Antisocial Personality, which is listed as a Personality Disorder. In any case, there is still the strongly held belief in both professional and public circles that individuals who are drug dependent are character disordered. In our patient population, there is little doubt that character pathology is present in many drug dependent individuals. The point is that if clinicians think only of character pathology when they evaluate drug dependent individuals, they will miss the diagnoses so far discussed, thus doing a disservice to their patients and themselves. In this context, only a careful clinical evaluation of each patient can lead to an appropriate treatment plan.

\section{Borderline Personality}

Consideration of so-called "Borderline Personality" has received considerable attention in the past decade. We see a number of individuals in our drug treatment program who fall into this category, though, admittedly, it is a poorly defined term. The following is a partial description of Border- 
line Personality from the proposed DSM 111: 3.The essential feature is instability in a variety of areas, including interpersonal relationships, behavior, mood, and self-image. No single feature is invariably present. Interpersonal relationships are often intense and unstable with marked shifts of attitude over time. Frequently there is impulsive and unpredictable behavior that is potentially physically selfdamaging. Mood is often unstable with marked shifts from normal mood to some dysphoric mood or with inappropriate intense anger or lack of control of anger. A profound identity disturbance may be manifested by uncertainty about several issues relating to identity, such as self-image, gender identity, long-term goals or values. There may be problems tolerating being alone, and chronic feelings of emptiness or boredom" (p. K20-21). This adequately describes many of the features in patients we would term as having a "Borderline Personality."Their lives are frequently in turmoil, and they present difficult treatment problems in drug treatment programs as well as in more traditional psychiatric settings. With time, I believe that the drug treatment field will add further depth to our understanding of these very troubled individuals.

\section{Stress and Addiction}

It is increasingly clear that individuals can use and become dependent on substances for timelimited periods, especially during periods involving stress. The experience of the Southeast Asian War demonstrated that thousands of American servicemen could become physically dependent on heroin during their tour of duty and stop their use of this powerful drug prior to their return to the United States. A report by Robbins (1973) showed that relatively few of these individuals continued their heroin use once they returned to the U.S. Among other things, this shattered the commonly held belief that heroin was such a powerful substance that use and addiction were synonymous. This also demonstrated that addiction to heroin need not be permanent and that the drug, though powerful and both physically and psychologically addicting, might not necessarily be more dangerous than many other drugs in common use (especially drugs in the sedative hypnotic category).

\section{Psychotropic Drugs}

Use of Psychotropic Drugs in Treatment of Drug Dependent Individuals. The question of whether or not to use psychotropic drugs as an adjunct in the overall treatment of drug dependent individuals is controversial. One argument frequently put forth is that it seems contradictory to use drugs to treat individuals who have clearly demonstrated an inability to control their drug use. Corollary to this argument is that the goal of treatment for drug dependent individuals should be attaining a drug free state. It is probable that for some individuals, becoming drug free is the best solution; for others, treatment with both addicting and non-addicting drugs appears appropriate. Methadone, for example, has only reluctantly been accepted as one drug in the clinical armamentarium for treating heroin and other narcotic addiction. I also feel that the judicious use of other psychotropic agents can be beneficial for certain drug dependent individuals. It has already been pointed out that antipsychotic drugs can be useful, either by themselves or in combination with methadone, in treating those drug dependent individuals with a history of psychosis. Similarly, we may find that tricyclic antidepressants are useful in alleviating the depression that is frequently present in patients addicted to narcotics and other drugs (most patients who present for treatment in our program are using several drugs and can be considered polydrug dependent). More data from the several depression studies currently being conducted should give valuable information on this issue. In a pilot study, Woody, O'Brien, and Rickels (1975) reported success in using doxepin $\mathrm{HCl}$ in treating a group of individuals on methadone maintenance. They discovered that individuals treated with doxepin $\mathrm{HCI}$ tended to need less methadone and also used fewer other drugs. We are currently conducting a similar double blind study 2 to test the effectiveness of doxepin HCI in a group of moderately to severely depressed patients on methadone maintenance. We hope to present the results of this study later this year.We have not used the various drugs in the sedative hypnotic category and don't at this time feel these would be useful, primarily because of their addictive potential. Nonetheless, many patients in our program regularly supplement their daily dose of methadone with diazepam, propoxyphene, alcohol, and other drugs to a lesser extent. We are hoping that the antianxiety effects of doxepin HCI will result in less sedative hypnotic drug use among subjects in the doxepin group in the depression study.

\section{Conclusions}

We have attempted to present data and clinical experiences from our work with drug dependent individuals to demonstrate that there are many etiologies of drug dependence. This demands that clinicians in the field carefully assess each patient to determine if there are underlying psychiatric causes for their drug use and subsequent dependence and to develop a treatment approach which addresses such causes. A rationale is presented for the use of psychotropic drugs as an adjunct in the treatment of certain drug dependent persons. The notion that drug dependence is related only to character pathology is rejected.

\section{REFERENCES}

[1] Berken, G. H., Stone, M. M. and Stone, S. K. 1978 "Methadone in Schizophrenic Rage: A Case Study." Am. J. Psychiatry. 135:248-249.

[2] Benvenuto, J. and Bourne, P. G. 1975 "The Federal Polydrug Abuse Project: Initial Report." J. Psych. Drugs. 7:115-120. 
[3] Chein, I., Gerard, D. L., Lee, R. S.- and Rosenfeld, E. 1964 The Road to H. New York, Basic Books, Inc.

[4] Gerard, D. L. and Kornetsky, C. 1954 "Adolescent Opiate Addiction: A Case Study. Psychiatric Quart. 28:367-380.

[5] Glover, E. 1956 "On the Etiology of Drug Addiction." In, On the Early Development of Mind. New York, International Universities Press.

[6] Khantzian, E. J. 1974 "Opiate Addiction: A Critique of Theory and . Some Implications for Treatment." Am. J. Psychotherapy. 28:59-70.

[7] Khantzian, E. J. 1978 "The Ego, the Self and Opiate Addiction: Theoretical and Treatment Considerations." Int. Review Psychoanalysis. 5:189-198.

[8] Kolb, L. 1927 "Clinical Contributions to Drug Addiction: The Struggle for Cures and the Conscious Reasons for Relapse. J. Nerv. Ment. Dis. 66:22-43.

[9] Krystal, H. and Raskin, H. A. 1970 Drug Dependence: Aspects of Ego Functions. Detroit. Wayne State University Press.

[10] McKenna, G. J. 1978 "The Drug/Alcohol/Psychiatry Interface." Critical Concerns in the Field of Drug Abuse: National Drug Abuse Conference, Inc. New York. Marcel-Dekker, Inc.

[11] McKenna, G. J., Fisch, A., Levine, M., Patch, V. and anyes, A. 1973 "The Use of Methadone as a Psychotropic Agent." Proceedings of the Fifth National Methadone Conference. Washington, D.C.

[12] McKenna, G. J., and Khantzian, E. J. 1979 "Ego Functions and Psychopathology in Narcotics and Polydrug Users." Int. J. Addictions. 14, No. 2.

[13] Rado, S. 1933 "The Psychoanalysis of Pharmacothymia. Psychoanalytic Q. 2:1-23.

[14] Robins, L. N. 1973 "The Vietnam Drug User Returns." Special Action Office Monograph, Series A., No. 2. Washington, D.C. U.S. Government Printing Office.
[15] Senay, E. C., Dorus, W. and Yufit, R. 1977 "Depression in Drug Abusers." Paper presented at the American Psychiatric Association Convention. Toronto.

[16] Stauss, F. F., Ousley, N. and Carlin, A. 1977 "Psychopathology and Drug Abuse: An MMPI Comparison of Polydrug Abuse Patients with Psychiatric Inpatients and Outpatients." Addictive Behaviors. 2:75-78.

[17] Treece, C. J. 1977 "Narcotic Use in Relation to Selected Ego Functions among Incarcerated Women." Unpublished doctoral dissertation. Boston University.

[18] Vaillant, G. E. 1966 "A 12-Year Follow-Up of New York Narcotic Addicts, III: Some Social and Psychiatric Characteristics. Arch. General Psychiatry. 15:599-609.

[19] Weissman, M., Slobetz, F., Prusoff, B., Mezritz, M. and Howard, P. 1976 "Clinical Depression among Narcotics Addicts Maintained on Methadone in the Community." Am. J. Psychiatry. 133:1434-1438.

[20] Wesson, D. R., Smith, E. and Lerner, S. 1975 "Streetwise and Nonstreetwise Polydrug Typology." J. Psychedelic Drugs. $7: 121134$.

[21] Wikler, A. 1952 "A Psychodynamic Study of a Patient During Experimental SelfRegulated Readdiction to Morphine. Psych. Q. 26:270.

[22] Wikler, A. and Rasor, R. W. 1953 "Psychiatric Aspects of Drug Addiction." Am. J. Med. 14:556-570.

[23] Wishnie, H. 1974 "Opioid Addiction: A Marked Depression. In Lesse, S. (Ed.), Masked Depression. New York. J. Aronson, Inc.

[24] Woody, G. E., O'Brien, C. P. and Rickels, K.1975 " Depression and Anxiety in Heroin Addicts: A Placebo-Controlled Study of Doxepin in Combination with Methadone." Am. J. Psych. 132:447-450.

[25] Wurmser, L. 1974 "Psychoanalytic Considerations of the Etiology of Compulsive Drug Use." J. Am. Psych. Assoc. 22:820-843. 